\title{
Unexpected effects of a prior feedback letter and a professional layout on the response rate to a mail survey in Geneva
}

\author{
Jean-François Etter, Thomas V Perneger, Jean-Dominique Laporte
}

\begin{abstract}
Obtaining high response rates in mail surveys is always a challenge. Several methods have been proposed to increase response. Sending participants a letter a few days before the questionnaire was effective in some studies ${ }^{12}$ but had a negative impact in another. ${ }^{3}$ Giving special attention to the questionnaire layout was also effective, ${ }^{4}$ although the effect was not always very important. ${ }^{2}$ We tested whether a prior feedback letter and an attractive questionnaire layout increased the response rate to a postal health survey conducted in Geneva, Switzerland, in 1994.
\end{abstract}

\section{Methods}

This survey was the third in a series of annual surveys conducted in a cohort of health insurance members to evaluate innovations in insurance contracts. ${ }^{5}$ Questions covered use of health services, health status (SF-36), and satisfaction with medical care. Eligible participants were Geneva residents, 32 years old on average (range 20-46); 50\% were men. Potential participants were randomised in a two way factorial trial: (1) to receiving or not, two weeks before the first survey package, a letter informing them of the results of previous surveys in which they had participated and announcing the next survey; and (2) to receiving the initial questionnaire either in a standard layout (black ink on white paper, prepared on a standard word processor) or in a professional layout (three colours, various fonts, additional enhancements). The best layout was to be used in reminder mailings. Thus the study was divided in a "randomised layout" phase (days 1-18 of data collection) and a "best layout" phase (days 19-111), during which up to five reminder mailings used the standard layout questionnaire for all. As our initial address list was one year old, 282 addresses were invalid and only 954 of 1236 persons were eligible for the "randomised layout" phase, 176 addresses were retrieved later but were not exposed to the ran- domised interventions. $\chi^{2}$ Tests were used to compare groups on dichotomous variables and $t$ tests on continuous variables.

\section{Results}

During the "randomised phase", the professional layout had a negative effect on response $(-6.8 \%$, table 1$)$. The prior letter had no statistically significant effect. During the "best layout" phase, the response rate was similar in the two "layout" groups, but persons who had received a prior letter participated more than persons who had not. This difference was not statistically significant. We found no interactions between incentive groups, neither during the "randomised phase" nor during the "best layout phase". By the end of data collection, there were no significant differences in response rates among the incentive groups.

During the "randomised phase", no interactions were detected between age, sex, and incentive groups, which means that the incentives did not cause selection bias on age or sex. Among persons who answered during the "randomised phase", the number of missing items, satisfaction scores with medical care, and the number of medical visits in the past year were similar in all incentive groups. However, respondents in the "standard layout" group reported better health status for four of eight SF-36 dimensions (role emotional, social functioning, mental health, general health). These statistically significant differences amounted to about 0.18 standard deviations.

\section{Discussion}

The prior letter neither improved nor decreased participation, which conflicts with previous work. ${ }^{1-3}$ The impact of a prior letter may not be generalisable across populations and types of surveys.

In contrast with expectations, the professional layout reduced the response rate. Several respondents commented that the questionnaire 9 May 1997

Table 1 Response to a mail survey, according to type of questionnaire layout, and to prior receipt of a feedback letter

\begin{tabular}{|c|c|c|c|c|c|c|c|c|c|c|}
\hline \multirow[b]{2}{*}{ Incentive group } & \multirow[b]{2}{*}{$\begin{array}{l}\text { Intended } \\
\text { sample }\end{array}$} & \multicolumn{3}{|c|}{ Randomised layout phase (Days 1-18) } & \multicolumn{3}{|c|}{ Best layout phase (Days 19-111) } & \multicolumn{3}{|c|}{ Overall (Days 1-111) } \\
\hline & & Eligible & $\begin{array}{l}\text { Response } \\
\text { rate }\end{array}$ & p Value & Eligible $^{\star}$ & $\begin{array}{l}\text { Response } \\
\text { rate }\end{array}$ & p Value & Eligible & $\begin{array}{l}\text { Response } \\
\text { rate }\end{array}$ & $p$ Value \\
\hline $\begin{array}{l}\text { Participants randomised in trial } \\
\text { Layout }\end{array}$ & 1236 & 954 & 58.8 & - & 393 & 72.5 & - & $954^{\star}$ & 88.7 & - \\
\hline Professional & 618 & 468 & 55.3 & 0.03 & 209 & 74.6 & 0.32 & $468^{\star}$ & 88.7 & 1.0 \\
\hline Standard & 618 & 486 & 62.1 & & 184 & 70.1 & & $486^{\star}$ & 88.7 & \\
\hline \multicolumn{11}{|l|}{ Prior feedback letter } \\
\hline Yes & 618 & 471 & 57.1 & 0.29 & 202 & 75.2 & 0.21 & $471^{\star}$ & 89.4 & 0.50 \\
\hline No & 618 & 483 & 60.5 & & 191 & 69.6 & & $483^{\star}$ & 88.0 & \\
\hline All participants & 1236 & - & - & - & - & - & - & 1130 & 86.3 & - \\
\hline
\end{tabular}

^Valid address available since first mailing. 
was "too luxurious" and protested its presumed high cost. This may have antagonised some people to the point of not responding. In addition, this questionnaire was spread over more pages and appeared thicker than the standard questionnaire, which may have discouraged some potential respondents. Whatever its mechanism, this detrimental effect could possibly have been avoided with appropriate pre-tests. Fortunately, the initial loss of respondents was recovered in subsequent mailings.

The choice of layout also biased the measurement of health status. Whether this reflects a direct effect of the layout on responses (information bias), differential enrolment (selection bias), or chance, remains uncertain.
Funding: this work was funded jointly by the Institute of Social and Preventive Medicine of the University of Geneva, by the insurance company Avenir, and by grants 3233-32609.91 and 32-39692.93 from the Swiss National Science Foundation.

Conflicts of interest: none.

$1 \mathrm{Yu}$ J, Cooper H. A quantitative review of research design effects on response rates to questionnaires. Fournal of Marketing Research 1983;20:36-44.

2 Kanuk L, Berenson C. Mail surveys and response rates: a literature review. Fournal of Marketing Research 1975;12: 440-53.

3 Jobber D, Sanderson S. The effect of a prior letter and a colored questionnaire paper on mail survey response rates. fournal of the Market Research Society 1983;25:339-49.

4 Dillman DA, Sinclair MD, Clark JR. Effects of questionnaire length, respondent-friendly design, and a difficult question on response rates for occupant-addressed census mail surveys. Public Opinion Quarterly 1993;57:289-304.

5 Perneger TV, Etter JF, Rougemont A. Switching Swiss enrollees from indemnity health insurance to managed care: the effect on health status and satisfaction with care. Am $\mathcal{F}$ Public Health 1996;86:388-93. 